\title{
Feedback simulation of duct design for alkali exhaust system in a semiconductor factory
}

\author{
Wen-Liang Chen ${ }^{\text {a,* }}$, Huei-Jiunn Chen ${ }^{\mathrm{b}}$, Sih-Li Chen ${ }^{\mathrm{c}}$ \\ ${ }^{a}$ Department of Product Design, Shu-Te University, Kaohsiung, Taiwan \\ ${ }^{\mathrm{b}}$ Department of Air Conditioning and Refrigeration, National Taipei University of Technology, Taipei, Taiwan \\ ${ }^{\mathrm{c}}$ Department of Mechanical Engineering, National Taiwan University, Taipei, Taiwan
}

Received 21 October 2005; received in revised form 19 December 2005; accepted 23 December 2005

\begin{abstract}
Duct design for an exhaust system must not only considers the demand of volume flow rate, but also takes into consideration a number of issues including system pressure balance, velocity constraint, space limitation and energy conservation. Conventional duct design methods either fail to achieve pressure equilibrium or offer poor control of flow velocity or duct diameter. A new design method that comprises two major calculation procedures: system sizing and rating is proposed. Duct system sizing problem is solved by the initial design from the conventional design methods. Feedback simulation provides the rating procedure for system actual operating process. An example is presented in this study to understand the characteristics of the proposed method. It demonstrates that the new duct design method contains a simple computation procedure and considers the pressure equilibrium under certain limits on space or flow velocity. It also provides the energy conservation strategies for the actual operating process during the design stage.
\end{abstract}

(C) 2006 Elsevier B.V. All rights reserved.

Keywords: Feedback simulation; Duct design; Exhaust system

\section{Introduction}

An optimum air duct system transports the required amount of conditioned, recirculated, or exhausted air to the specific space and meets the following requirements: (1) an optimum duct system layout within the allocated space, (2) a satisfactory system pressure balance, (3) space noise level lower than the allowable limits, and (4) optimum energy cost and initial cost. Deficiencies in duct design can result in systems that operate incorrectly and increase the initial or running cost.

Most conventional heating, ventilating, and air-conditioning (HVAC) duct sizing designs use the equal friction method [1]. This method may be simple, but they fail to achieve pressure balance or offer poor control of flow velocity or duct diameter. For a system originally designed with unbalanced pressure, once in operation, the system will automatically adjust the velocity and volume flow rate in all duct sections to achieve equal total pressure loss on all paths. In this case, the volume

\footnotetext{
* Corresponding author. Tel.: +886 7 6158000x3812; fax: +886 7 6158000x3899.

E-mail address: cwl@mail.stu.edu.tw (W.-L. Chen).
}

flow rate will not meet the original design requirements. On-site balancing adjustment after project completion becomes necessary. However, the pressure-balancing procedures for air distribution systems is rather complicated [2]. It usually takes long time to proportional adjust branch dampers until each terminal has the proper air volume. If the factory is expanded or the duct layout is changed, the pressure balance needs to be readjusted in order for the system to reach equilibrium. In some cases, overly large fans must be installed to make up for poor design, which add to the extra costs.

T-method proposed by Tsal et al. [3,4] is the most comprehensive tool in duct sizing design. Although it enables the system to achieve system pressure balance with the life cycle cost taken into account, T-method offers poor control of flow velocity or duct diameter [5]. Moreover, it fails to give method for flexible design and an insight into the actual operating condition during the design stage. With the assistance of simulation rating procedures in the design can minimize the impact of this disadvantage. Conventional duct system simulation rating method, proposed by Tsal et al. [6], adopts the open loop simulation method. Due to lack of feedback, it only possesses the simulation feature without the correction function. As a result, the velocity and volume flow rate will not meet the design requirements. 


\begin{tabular}{|ll|}
\hline \multicolumn{2}{|c|}{ Nomenclature } \\
$C$ & local loss coefficient, dimensionless \\
$C_{\mathrm{v}}$ & flow coefficient $\left(\mathrm{Pa}\left(\mathrm{s} / \mathrm{m}^{3}\right)^{0.5}\right)$ \\
$D$ & duct diameter $(\mathrm{m})$ \\
$f$ & friction factor, dimensionless \\
$K_{\mathrm{S}}$ & sectional flow conductance coefficient $\left(\mathrm{m}^{3} / \mathrm{s} /\right.$ \\
& $\left.\mathrm{Pa}^{0.5}\right)$ \\
$K_{\mathrm{S}, \mathrm{sys}}$ & system flow conductance coefficient $\left(\mathrm{m}^{3} / \mathrm{s} / \mathrm{Pa}^{0.5}\right)$ \\
$L$ & duct length $(\mathrm{m})$ \\
$\Delta P$ & total pressure loss $(\mathrm{Pa})$ \\
$\Delta P_{\mathrm{D}}$ & dynamic loss of damper $(\mathrm{Pa})$ \\
$P_{\text {fan }}$ & fan total pressure $(\mathrm{Pa})$ \\
$P_{\text {sys }}$ & system total pressure $(\mathrm{Pa})$ \\
$\Delta P_{\text {sys }}$ & system pressure loss $(\mathrm{Pa})$ \\
$\Delta P_{\mathrm{T}}$ & the total friction loss and the total dynamic loss \\
& except dampers $(\mathrm{Pa})$ \\
$Q$ & duct airflow $\left(\mathrm{m}^{3} / \mathrm{s}\right)$ \\
$Q_{\text {fan }}$ & fan airflow rate $\left(\mathrm{m}^{3} / \mathrm{s}\right)$ \\
$Q_{\text {sys }}$ & system airflow rate $\left(\mathrm{m}^{3} / \mathrm{s}\right)$ \\
Greek & symbol \\
$\rho$ & air density $\left(\mathrm{kg} / \mathrm{m}^{3}\right)$ \\
&
\end{tabular}

The significance of the proposed rating method is in correcting system design values based on operation results in order to achieve the goal of precise design, which is very similar to the feedback control in dynamic system. System devices utilize error signal and correction procedure to adjust the control variable. With the assistance of correction procedure, the deviation of velocity and volume flow rate caused by unbalanced pressure can be reduced. After a few times of system simulation, and corrections, proper rating design can minimize the error in the volume flow rate within an acceptable range.

\section{Proposed duct design method}

Fig. 1 shows the design flowchart for the proposed duct design method, which includes four major steps: inputting given system dimensions and limitations, initial duct design, system simulation and correction procedures. The first step is to give the system dimensions and limitations, which include (1) basic information: such as duct system layout, liquid physical property, and duct materials; (2) system requirements: such as volume flow rate, length and cross section shape; (3) duct information: such as the loss coefficient of various accessories

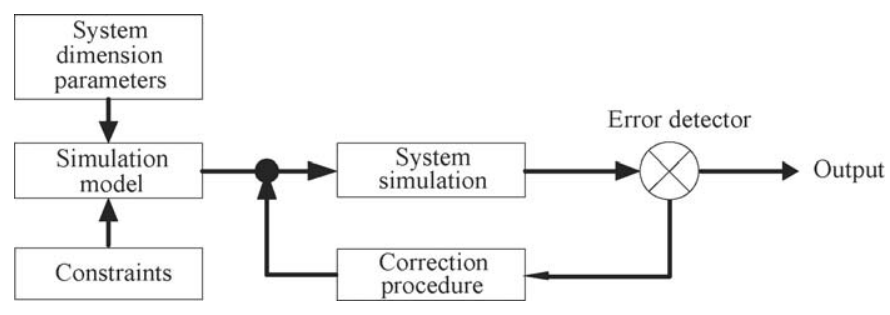

Fig. 1. The proposed design method. and equipments [1,7]; (4) safety concerns: such as the minimum velocity for safety [2] or the maximum velocity to prevent vibrations and noise [8]; (5) cost concern: such as total duct surface area or the volume flow rate.

The second step is to choose the initial design method and to initiate the duct design. Initial design method can adopt one of the conventional duct design methods with designating given system conditions and limitations. In this paper we use equal friction method as the initial design method. This method sizes the air duct based on the fact that at various duct sections the duct frictional loss per unit length, $F_{\mathrm{R}}$, which is defined as follows, always remains constant:

$F_{\mathrm{R}}=\frac{0.11((\varepsilon / D)+(17 \pi D v / Q))^{0.25}}{D} \times \frac{\rho\left(16 Q^{2} / \pi^{2} D^{4}\right)}{2}$

From the specified unit friction rate and required flow rate, the diameter of each duct section may be obtained from Eq. (1). Then the pressure loss of each section can be obtained from the Darcy-Weisbach equation, and the maximum pressure loss for all paths can be determined. The maximum total pressure losses of the duct system are known as the basis for the selection of the fan. The sizes of duct diameter and fan can be determined.

Once the sizing problem has been solved. The third step is to perform the system rating through system simulation and correction procedure. System simulation determines the flow in each duct section of an existed system with a known operating fan performance curve. For a system originally designed from initial design method with unbalanced pressure, while in operation, the system will automatically adjust the velocity and volume flow rate in all duct sections to achieve equal total pressure loss on all paths. In this case, the velocity and volume flow rate will not meet the original design requirements. System simulation is performed after the initial design or the correction process is completed in order to verify the actual operating performance of the system. The simulation model proposed by Tsal et al. [6] is adopted in this paper. It includes the major procedures of system condensing, fan operating point and system expansion.

If $\mu$ is defined as $\mu=\left(\frac{f L}{D}+\sum C\right) \times D$, the volume flow rate can be identified in terms of diameter and pressure loss as:

$Q=\frac{\pi}{\sqrt{8}}\left(\frac{D^{5}}{\mu \rho}\right)^{0.5} \sqrt{\Delta P}$

By introducing the duct section characteristic $K_{\mathrm{S}}$ :

$K_{\mathrm{S}}=\frac{\pi}{\sqrt{8}}\left(\frac{D^{5}}{\mu \rho}\right)^{0.5}$

Then, the flow rate at a duct section becomes:

$Q=K_{\mathrm{S}} \sqrt{\Delta P}$

The procedure of system condensing condenses a branched tee into a single imaginary duct section with identical hydraulic characteristics. Two or more converging or diverging sections and the common section at a junction can be replaced by one 
condensed section. From junction to junction in the direction to the root section, the entire system, including supply and return subsystems, can be condensed into one imaginary section, i.e., a single resistance. It can be divided into series, parallel, and a tee to derive a system curve.

The system in Fig. 2a contains two duct sections connected in series. To introduce imaginary duct sections 1 and 2 this section must satisfy the following conditions:

$Q_{1-2}=Q_{1}=Q_{2}$

$\Delta P_{1-2}=\Delta P_{1}+\Delta P_{2}$

Substituting Eq. (4) into Eq. (5b) obtains:

$$
\frac{Q_{1-2}^{2}}{K_{\mathrm{S}}^{2}}=\frac{Q_{1}^{2}}{K_{\mathrm{S}}^{2}}+\frac{Q_{2}^{2}}{K_{\mathrm{S}}^{2}}
$$

Also substituting Eq. (5a) into Eq. (5c), the imaginary duct section characteristics can be obtained as:

$K_{\mathrm{S}_{1-2}}=\left(K_{\mathrm{S}_{1}}^{-2}+K_{\mathrm{S}_{2}}^{-2}\right)^{-0.5}$

Two sections 1 and 2, in parallel can be condensed into an imaginary sections 1 and 2, as shown in Fig. 2b. The condensed section must satisfy the following conditions:

$Q_{1-2}=Q_{1}+Q_{2}$

$\Delta P_{1-2}=\Delta P_{1}=\Delta P_{2}$

From Eq. (4) and Eqs. (7a) and (7b), $K_{\mathrm{S}}$ of condensed duct sections 1 and 2 is:

$K_{\mathrm{S}_{1-2}}=K_{\mathrm{S}_{1}}+K_{\mathrm{S}_{2}}$

This equation is derived when the degree of a node is two. Similarly, if the degree of a node is more than 2 (i.e. the conductance coefficient is $K_{\mathrm{S}_{1}}, K_{\mathrm{S}_{2}}, \ldots, K_{\mathrm{S}_{n}}$ ), this equation becomes:

$K_{\mathrm{S}_{1-n}}=\sum_{i=1}^{n} K_{\mathrm{S}_{i}}$

Consider the tee shown in Fig. 2c, which contains one node, two sections 1 and 2 in parallel, and one section 3 in series. First, condense the parallel sections 2 and 3 to form sections 2 and 3 , and then condense series sections 2 and 3 and 1 into sections $1-3$ to obtain:

$K_{\mathrm{S}_{1-3}}=\left[K_{\mathrm{S}_{1}}^{-2}+\left(K_{\mathrm{S}_{2}}+K_{\mathrm{S}_{3}}\right)^{-2}\right]^{-0.5}$
When the system condensing is completed, the duct system arrives at only one fan and one imaginary duct section. Therefore, from Eq. (4) we obtain Eq. (11), where $K_{\mathrm{S}}$ is replaced by the coefficient of conductance for the system, $K_{\mathrm{S} \text {,sys. }}$. The system curve becomes:

$Q_{\mathrm{sys}}=K_{\mathrm{S}, \mathrm{sys}} \sqrt{\Delta P_{\mathrm{sys}}}$

When the system is operated, the fan actual operating point is at the intersection of system curve and fan performance curve. That is $Q_{\text {sys }}=Q_{\text {fan }}$ and $P_{\text {sys }}=P_{\text {fan }}$.

System expansion is followed after locating the fan operating point. The expansion procedure distributes the fan flow rate $Q_{\text {fan }}$ through out the system sections. Knowing system flow and pressure, the previously condensed imaginary duct section is expanded into the original system with flow distributed in accordance with the ratio of pressure losses calculated in the system condensing step. The expansion procedure stars at the root section and continues in the direction of the terminals. During the design process, system expansion is conducted section by section from upstream to downstream.

The fourth step is to perform the correction procedure. The most notable feature of the proposed rating method is the establishment of correction procedures based on the characteristics of the duct system. Suppose there are $N$ paths in an exhaust duct system. The volume flow rates required in the paths are $Q_{1}, Q_{2}, \ldots, Q_{N}$. The total volume flow rate needed by the system is:

$Q_{\text {sys }}=\sum_{n=1}^{n=N} Q_{n}$

The friction and dynamic losses of ducts and branches except dampers for each path are $\Delta P_{\mathrm{T}, 1}, \Delta P_{\mathrm{T}, 2}, \ldots, \Delta P_{\mathrm{T}, N}$, and the dynamic losses created by the dampers in the paths are $\Delta P_{\mathrm{D}, 1}$, $\Delta P_{\mathrm{D}, 2}, \ldots, \Delta P_{\mathrm{D}, N}$. Then the total friction and dynamic loss of each path is:

$\Delta P_{n}=\Delta P_{\mathrm{T}, n}+\Delta P_{\mathrm{D}, n}, \quad n=1,2, \ldots, N$

The total flow rate provided by the fan must meet the total volume flow rate required by all paths. Therefore, the total volume flow rate provided by the fan is:

$Q_{\mathrm{fan}}=Q_{\mathrm{sys}}=\sum_{n=1}^{n=N} Q_{n}$

Since the flow rate provided by the fan is given, the fan operating point can be obtained through the fan performance curve. Through this operating point, the total fan pressure $P_{\text {fan }}$

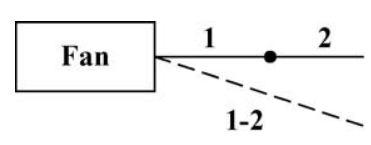

(a)

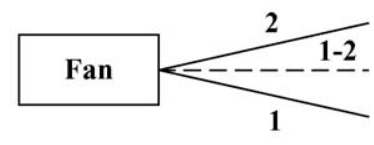

(b)

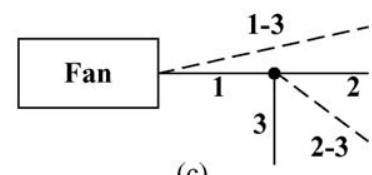

(c)

Fig. 2. (a) Condensing two sections connected in series; (b) condensing two sections connected in parallel; (c) condensing three sections connected in tee. 
can be obtained and it should be equal to the total friction and dynamic loss of one path. That is:

$P_{\text {fan }}=\Delta P_{n}$

To meet the pressure balance requirement of all paths, the dynamic loss created by dampers can be obtained as:

$\Delta P_{\mathrm{D}, n}=P_{\text {fan }}-\Delta P_{\mathrm{T}, n}$

Then the flow coefficient created by dampers in various paths can be obtained through Eq. (16) as:

$C_{\mathrm{v}}=\frac{\Delta P_{\mathrm{D}, n}}{\sqrt{Q_{n}}}$

Adjust the flow coefficients of dampers at all paths from Eq. (17) and substitute the corrected values into the system simulation, until the error between the simulated flow rate and the designed flow rate is under $5 \%$, the simulation is completed. The results of flow coefficients are converted to the operating angle of the dampers at each path.

\section{Example illustration}

A real case of alkali gas exhaust system in a semiconductor factory is designed and simulated though the new duct design method. As described in Fig. 1, the design constraints are determined by semiconductor factory operation requirement. The most important issues are the designation of a safe ventilation velocity and the total volume flow rate of system ventilation, as listed in Table 1 . The volume flow rate depends on the amount of waste gas produced. The duct length of the system is determined by the position of the machine and the building's structure. The conduits used in the system are regular galvanized spiral ducts with the absolute roughness being $3 \times 10^{-4} \mathrm{~m}$. The upper and lower velocity limits are $15.0 \mathrm{~m} / \mathrm{s}$ and $5.0 \mathrm{~m} / \mathrm{s}$. The upper and lower limits of the safe velocity are decided by such parameters as the type of gas emission, humidity, vibration, and noise.

Fig. 3 shows the layout of alkali gas exhaust system in a semiconductor factory. Codes are given to different duct sections, dampers, and paths. Duct sections are named on the basis of their terminal sections, duct diameters, and cross section shapes. Dampers are installed at the terminals of the ducts. They are used to balance and adjust the volume flow rate required by various machines. There are a total of 56 duct sections including 14 terminal sections and 14 paths. Table 1 shows both the flow rate at each duct section and the corresponding length. Table 2 indicates the path number for each route of exhaust gas from the terminal section (machine location) to the fan. The exhaust gas is expelled to the top floor through the scrubber and then is emitted outdoors.

After inputting the system requirements and parameters, duct diameters for all sections and fan capacity can be obtained from the equal friction method. The total pressure losses of all paths are already known to serve as the basis for the selection of fan. The results are shown in Table 2. It is obvious that there is a considerable discrepancy in the pressure
Table 1

Duct sections and flow rate requirements

\begin{tabular}{rrrllr}
\hline $\begin{array}{l}\text { Duct } \\
\text { section }\end{array}$ & $\begin{array}{l}\text { Flow rate } \\
\left(\mathrm{m}^{3} / \mathrm{s}\right)\end{array}$ & $\begin{array}{c}\text { Length } \\
(\mathrm{m})\end{array}$ & $\begin{array}{l}\text { Duct } \\
\text { section }\end{array}$ & $\begin{array}{l}\text { Flow rate } \\
\left(\mathrm{m}^{3} / \mathrm{s}\right)\end{array}$ & $\begin{array}{r}\text { Length } \\
(\mathrm{m})\end{array}$ \\
\hline 1 & 10.62 & 1.00 & 29 & 1.72 & 21.40 \\
2 & 8.28 & 38.00 & 30 & 3.05 & 1.00 \\
3 & 0.37 & 3.80 & 31 & 3.05 & 13.40 \\
4 & 0.37 & 3.00 & 32 & 1.72 & 21.40 \\
5 & 0.37 & 1.50 & 33 & 1.33 & 1.00 \\
6 & 0.37 & 9.60 & 34 & 1.33 & 6.00 \\
7 & 0.37 & 12.60 & 35 & 0.72 & 18.00 \\
8 & 7.91 & 0.50 & 36 & 0.61 & 1.00 \\
9 & 7.91 & 2.50 & 37 & 0.61 & 14.40 \\
10 & 7.91 & 4.50 & 38 & 0.61 & 22.40 \\
11 & 7.91 & 10.50 & 39 & 2.34 & 1.00 \\
12 & 7.91 & 14.70 & 40 & 2.34 & 3.20 \\
13 & 7.91 & 4.00 & 41 & 2.34 & 2.00 \\
14 & 2.11 & 0.50 & 42 & 0.82 & 2.00 \\
15 & 2.11 & 6.40 & 43 & 1.52 & 15.00 \\
16 & 2.11 & 20.40 & 44 & 1.17 & 3.00 \\
17 & 1.06 & 23.00 & 45 & 0.70 & 1.00 \\
18 & 1.05 & 2.00 & 46 & 0.70 & 7.00 \\
19 & 1.05 & 47.60 & 47 & 0.70 & 12.00 \\
20 & 1.05 & 20.20 & 48 & 0.47 & 12.00 \\
21 & 5.80 & 0.50 & 49 & 0.33 & 17.50 \\
22 & 5.80 & 57.00 & 50 & 0.33 & 10.40 \\
23 & 5.80 & 6.00 & 51 & 0.33 & 21.50 \\
24 & 0.53 & 22.00 & 52 & 0.82 & 15.00 \\
25 & 5.270 & 16.00 & 53 & 0.82 & 24.00 \\
26 & 0.500 & 22.00 & 54 & 0.82 & 5.00 \\
27 & 4.770 & 1.00 & 55 & 0.56 & 0.26 \\
28 & 4.770 & 5.40 & 56 & & \\
\hline & & & & & \\
\hline
\end{tabular}

loss on different paths. The duct design results from equal friction cannot achieve a pressure balance. There is a sizeable error in the volume flow rate between various terminal sections and design requirements during system operation. The results also show that path no. 9 has the largest total pressure drop of all, which makes it the "critical path" in duct design. The largest total friction and dynamic loss of all paths serves as the basis for the selection of the fan.

Table 3 compares the required flow rates with the flow rates and velocities at the first simulation at each section. The first simulation means that the dampers located at each terminal section are fully open. It shows that in addition to a large discrepancy in volume flow rate, the velocities in some duct sections (foe example, nos. 35 and 38) are obviously too low. Since there is a considerable discrepancy in volume flow rate on terminal sections, it is necessary to correct the flow rate.

The correction procedure will initiate by adjusting the damper positions at each terminal section and then the system simulation model from the proposed method will generate the error between the simulated value and required value. If the error is greater than $5 \%$, a feedback signal is returned to the correction procedure and the damper flow coefficient is corrected automatically. The system simulation and the correction procedure will be repeated and iterated by adjusting the damper position, until the error is smaller than the requirement value. After eight iterations of corrections, the design of the entire process exhaust system is completed. It can be seen from Table 4 that the volume flow rate needed for the 


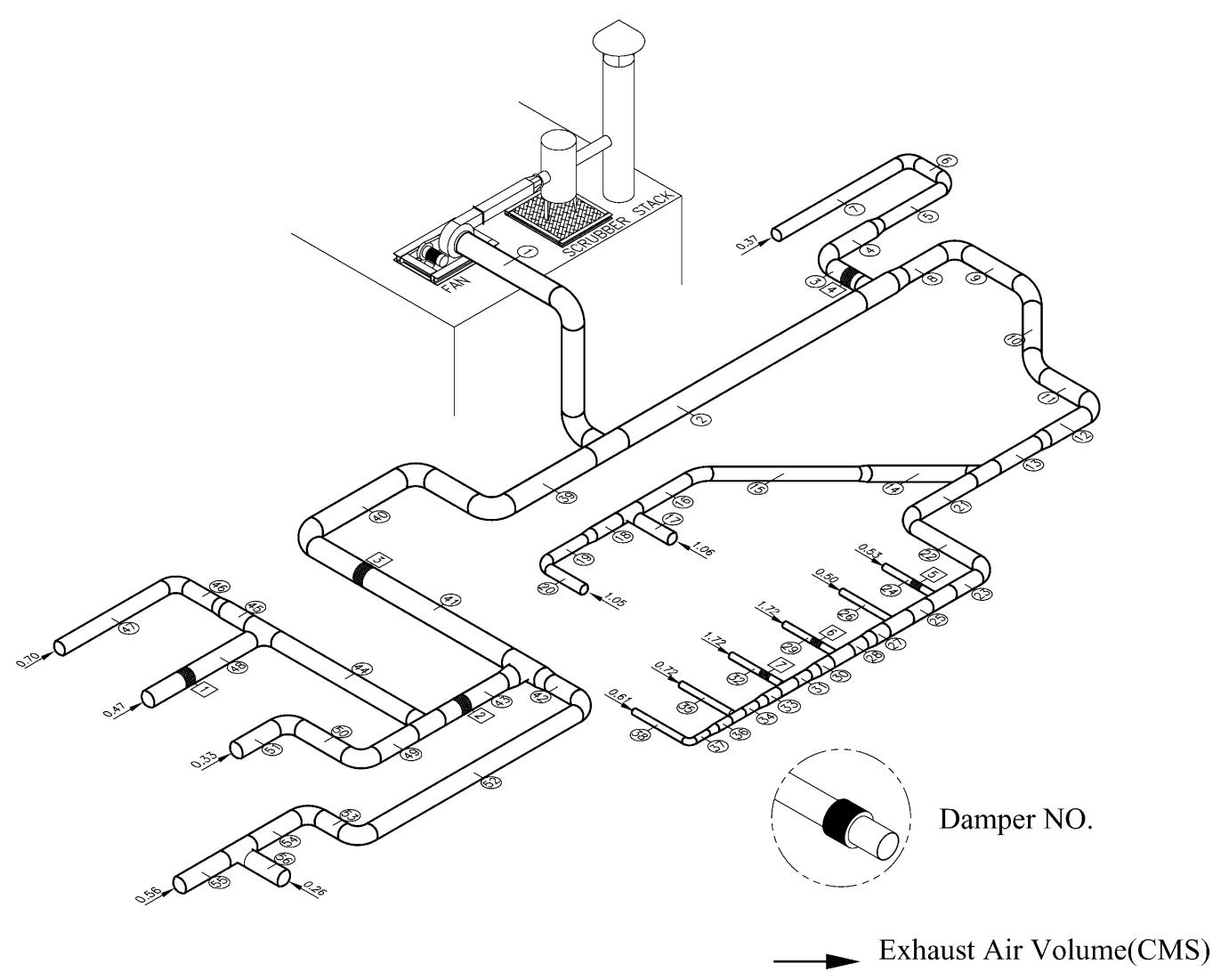

Fig. 3. Duct layout of an alkali exhaust gas system for a semiconductor factory (designed from equal friction method).

section at the exhaust alkali gas system calculated from the proposed design method is very close to the volume flow rate required by the design requirements.

Fig. 4 shows the correlation between the extents of the volume flow rate error at each iteration correction. Symbol 0 represents the results from the first simulation, as the dampers are fully open. Symbols 1-8 indicate the corrected results through the feedback simulation during each iteration correction by adjusting the dynamic pressure drop of dampers to meet the system pressure balance. Each iteration correction characterizes the feedback correction times in the simulation procedures. As the iteration of feedback corrections increases, the error is effectively reduced. The volume flow rate in first simulation, as compared with that at the original design requirements, has an average error around $45 \%$. The volume flow rate predicted from the proposed design method (iteration 8 ) has an average error around $4.5 \%$. It should be noted that the discrepancy in volume flow rate error for the proposed method is primarily because of system safety concerns in the design procedure. That is, a fan provide volume flow rate greater than the required volume flow rate to meet the demand of allowance of safety.

Table 2

Duct designs results at each path for pressure loss from equal friction method

\begin{tabular}{lll}
\hline Path no. & Pressure loss $(\mathrm{Pa})$ & Path \\
\hline 1 & 134.07 & Fan-1-2-3-4-5-6-7 \\
2 & 243.05 & Fan-1-2-8-9-10-11-12-13-14-15-16-17 \\
3 & 333.33 & Fan-1-2-8-9-10-11-12-13-14-15-16-18-19-20 \\
4 & 310.96 & Fan-1-2-8-9-10-11-12-13-21-22-23-24 \\
5 & 341.82 & Fan-1-2-8-9-10-11-12-13-21-22-23-25-26 \\
6 & 353.01 & Fan-1-2-8-9-10-11-12-13-21-22-23-25-27-28-29 \\
7 & 380.79 & Fan-1-2-8-9-10-11-12-13-21-22-23-25-27-28-30-31-32 \\
8 & 387.73 & Fan-1-2-8-9-10-11-12-13-21-22-23-25-27-28-30-31-33-34-35 \\
9 & 425.92 & Fan-1-2-8-9-10-11-12-13-21-22-23-25-27-28-30-31-33-34-36-37-38 \\
10 & 87.19 & Fan-1-39-40-41-43-44-45-46-47 \\
11 & 71.76 & Fan-1-39-40-41-43-44-48 \\
12 & 113.23 & Fan-1-39-40-41-43-49-50-51 \\
13 & 144.10 & Fan-1-39-40-41-42-52-53-54-55 \\
14 & 154.13 & Fan-1-39-40-41-42-52-53-54-56
\end{tabular}


Table 3

The first simulation results (symbol 0)

\begin{tabular}{lllll}
\hline $\begin{array}{l}\text { Duct } \\
\text { section }\end{array}$ & $\begin{array}{l}\text { Required } \\
\text { flow rate }\left(\mathrm{m}^{3} / \mathrm{s}\right)\end{array}$ & $\begin{array}{l}\text { Simulation } \\
\text { flow rate }\left(\mathrm{m}^{3} / \mathrm{s}\right)\end{array}$ & $\begin{array}{l}\text { Simulation } \\
\text { velocity }(\mathrm{m} / \mathrm{s})\end{array}$ & $\begin{array}{l}\text { Diameter } \\
(\mathrm{m})\end{array}$ \\
\hline 7 & 0.370 & 0.832 & 14.645 & 0.269 \\
17 & 1.060 & 1.604 & 12.830 & 0.399 \\
20 & 1.050 & 0.909 & 7.345 & 0.397 \\
24 & 0.530 & 0.692 & 9.354 & 0.307 \\
26 & 0.500 & 0.534 & 7.503 & 0.301 \\
29 & 1.720 & 1.512 & 8.354 & 0.480 \\
32 & 1.720 & 1.161 & 6.414 & 0.480 \\
35 & 0.720 & 0.455 & 4.872 & 0.345 \\
38 & 0.610 & 0.262 & 3.175 & 0.324 \\
47 & 0.700 & 1.054 & 11.611 & 0.340 \\
48 & 0.470 & 0.959 & 14.120 & 0.294 \\
51 & 0.330 & 0.448 & 8.632 & 0.257 \\
55 & 0.560 & 0.742 & 9.584 & 0.314 \\
56 & 0.260 & 0.236 & 5.438 & 0.235 \\
\hline
\end{tabular}

Table 4

Comparison of design required flow rate and simulated flow rate

\begin{tabular}{lllc}
\hline $\begin{array}{l}\text { Terminal } \\
\text { section }\end{array}$ & $\begin{array}{l}\text { Required flow } \\
\text { rate }\left(\mathrm{m}^{3} / \mathrm{s}\right)\end{array}$ & $\begin{array}{l}\text { Simulated flow } \\
\text { rate }\left(\mathrm{m}^{3} / \mathrm{s}\right)\end{array}$ & $\begin{array}{c}\text { Error } \\
(\%)\end{array}$ \\
\hline 7 & 0.37 & 0.376 & 1.62 \\
17 & 1.06 & 1.169 & 10.28 \\
20 & 1.05 & 1.188 & 13.14 \\
24 & 0.53 & 0.564 & 5.8 \\
26 & 0.50 & 0.512 & 2.40 \\
29 & 1.72 & 1.825 & 6.10 \\
32 & 1.72 & 1.727 & 0.41 \\
35 & 0.72 & 0.752 & 0.26 \\
38 & 0.61 & 0.636 & 4.26 \\
47 & 0.70 & 0.725 & 3.57 \\
48 & 0.47 & 0.492 & 4.68 \\
51 & 0.33 & 0.293 & 4.64 \\
55 & 0.56 & 0.576 & 2.86 \\
56 & 0.26 & 0.268 & 3.08 \\
\hline
\end{tabular}

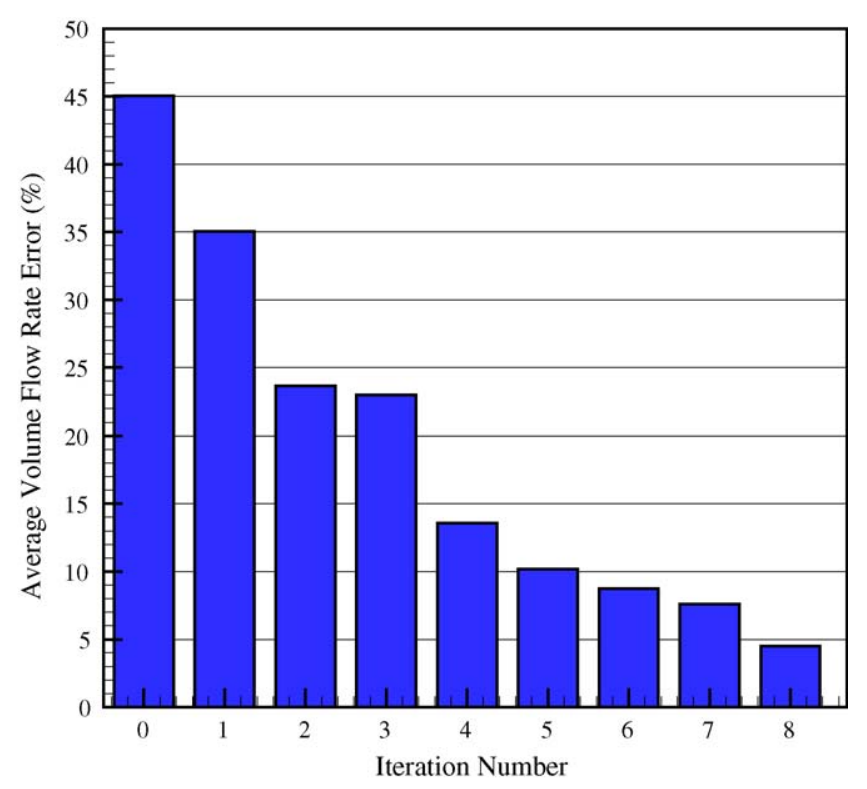

Fig. 4. Average volume flow rate error at each corrected level.
Table 5

Fan capacity requirements in each iteration design

\begin{tabular}{lll}
\hline Iteration no. & Fan total pressure $(\mathrm{Pa})$ & Fan volume flow rate $\left(\mathrm{m}^{3} / \mathrm{s}\right)$ \\
\hline 0 & 460.261 & 10.355 \\
1 & 489.870 & 10.980 \\
2 & 476.138 & 11.160 \\
3 & 470.156 & 11.235 \\
4 & 470.156 & 11.235 \\
5 & 471.365 & 11.220 \\
6 & 473.764 & 11.190 \\
7 & 474.954 & 11.175 \\
8 & 473.764 & 11.190 \\
\hline
\end{tabular}

Table 5 shows the results of fan total pressure and volume flow rate at each feedback iteration calculation. The change of system volume flow rate is very limited, while the fan total pressure increases around 3\%. The reason for the rise in fan total pressure is due to the adjustment of a pressure-balancing device. Damper positions are adjusted during each correction, which increase the resistance and raise the fan total pressure as the number of corrections increases. The proposed method also provides the energy conservation strategies for the actual operating condition during the design stage. The system operating cost is primarily determined by the fan energy consumption. The energy cost is correlated with the product of the fan volume flow rate and total pressure. Damper positions are corrected during the correction procedures, which raise the fan total pressure and increase the energy cost as the number of corrections gradually increases.

For the exhaust duct system, damper angle is usually adjusted to achieve system pressure balance. The purpose is to decrease the required flow rate by increasing system resistance. Though this method can achieve system balance, it increases the operation electrical cost. In order to achieve the two goals, system balance and energy saving, the fan speed control is an effective method. The article is to simulate by controlling the supply frequency to decrease the fan speed and by adjusting the damper position to decrease the dynamic loss. When the fan's speed at full load is $1450 \mathrm{rpm}$, set the speed to $1400 \mathrm{rpm}$, $1350 \mathrm{rpm}, 1300 \mathrm{rpm}, 1250 \mathrm{rpm}$, and $1200 \mathrm{rpm}$. When the speed is set at $1200 \mathrm{rpm}$ or below, the fan total pressure is balanced with the total friction and dynamic losses of exhaust duct system, while the simulated flow rate are no longer enough to meet the requirement of the system. The operation condition $1200 \mathrm{rpm}$ is thus set as the fan's minimum speed. When the speed is $1450 \mathrm{rpm}$, the annual operation expense is NT\$ $1,805,000$. As fan speed reduces to $1250 \mathrm{rpm}$, there saves NT\$ $1,173,250$ operation expense, a saving of $35 \%$. This is because when the speed of the fan decreases, the total pressure and flow provided by the fan decrease as well. It is not necessary to increase extra damper resistance to achieve balance.

The presented method develops an automatic correction procedure, which is based on the characteristics of flow distribution in the exhaust duct system. That is the fan operation point and the damper dynamic loss can be quickly obtained after iteration, which enables effective correction and reduces the simulation time. Therefore, the simulated damper positions 
of the duct system can provide an efficiency method to meet the system balance in the design stage. In addition in many practical projects commissioning is complicated and timeconsuming. The proposed method also can conduct to on-site system commissioning of a practical exhaust duct system. Based on the results, quick system balance and adjustment can be explored. After the loss coefficient database for duct devices is established, the computer program will automatically compute the loss coefficient. This saves designers the trouble of checking against related tables and figures all the time. As long as the program is accurate and the input data are correct, no mistake will occur in the computation results. Aided by highspeed computation, the time needed for the design can be substantially reduced. The article uses a Pentium 4 computer. The simulation takes only $1 \mathrm{~min}$ from start to end, as opposed to 1-2 months spent conducting on-site exhaust balance and adjustment, significantly saving time and money.

\section{Conclusions}

The case study presented in this paper shows that the application of new duct design method is feasible. During the design process, it often becomes necessary to change certain design parameters or alter the system layout due to limitations of the building's structure. In this case, designers simply change the computer input data to obtain new design results without spending considerable time in recalculation. Designers can also conduct online system simulation during the design stage in order to find design flaws and correct them. The energy conservation strategies for the exhaust duct system during the actual operating stages can be obtained. Therefore, in the face of the challenge of lower cost and shorter time in semiconductor industry, use of the proposed method in the design of the exhaust duct system can substantially improve the design efficiency, reduce work time and labor, which in turn raises the designer's competitiveness.

\section{References}

[1] ASHRAE, ASHRAE Handbook-Fundamentals, American Society of Heating, Refrigerating and Air-Conditioning Engineers Inc., Atlanta, 1997

[2] ASHRAE, ASHRAE Handbook-Heating, Ventilating and Air-Conditioning Applications, American Society of Heating, Refrigerating and AirConditioning Engineers Inc., Atlanta, 1995.

[3] R.J. Tsal, H.F. Behls, R. Mangel, T-method duct design. Part I: optimization theory, ASHRAE Transactions 94 (2) (1988) 90-111.

[4] R.J. Tsal, H.F. Behls, R. Mangel, T-method duct design. Part II: calculation procedure and economic analysis, ASHRAE Transactions 94 (2) (1988) $112-150$.

[5] H.R. Shiu, F.C. Ou, S.L. Chen, Optimization design of exhaust duct system in semiconductor factory using dynamic programming method, Building and Environment 38 (2003) 533-542.

[6] R.J. Tsal, H.F. Behls, R. Mangel, T-method duct design. Part III: simulation, ASHRAE Transactions 96 (2) (1990) 3-31.

[7] ASHRAE, Duct Fitting Database, American Society of Heating, Refrigerating and Air-Conditioning Engineers Inc., Atlanta, 1994.

[8] R.H. Howell, H.J. Sauer, W.J. Coad, Principles of Heating, Ventilating and Air Conditioning, American Society of Heating, Refrigerating and AirConditioning Engineers Inc., Atlanta, 1998. 